\title{
Prototype Manufacturing of Extruded Aluminum Aircraft Stringer Profiles with Continuous Reinforcement
}

\author{
T. Kloppenborg', a , T. Hammers ${ }^{2, b}$, M. Schikorra ${ }^{1, c}$, E. Kerscher ${ }^{2, d}$, \\ A. E. Tekkaya ${ }^{1, e}$, D. Löhe ${ }^{2, f}$ \\ ${ }^{1}$ Institute of Forming Technology and Lightweight Construction, Technical University of Dortmund, \\ Baroper Str. 301, 44227 Dortmund, Germany \\ ${ }^{2}$ Institute of Materials Science and Engineering 1, University of Karlsruhe, \\ Kaiserstr. 12, 76131 Karlsruhe, Germany \\ aThomas.Kloppenborg@iul.uni-dortmund.de, ${ }^{\text {b} T h i l o . H a m m e r s @ i w k 1 . u n i-k a r l s r u h e . d e, ~}$ \\ 'Marco.Schikorra@iul.uni-dortmund.de, 'Eberhard.Kerscher@iwk1.uni-karlsruhe.de, \\ `Erman.Tekkaya@iul.uni-dortmund.de, fDetlef.Loehe@iwk1.uni-karlsruhe.de
}

Keywords: Stringer profiles, extrusion, composite, seam weld

\begin{abstract}
For an increase in safety against crack initiation and growth in metallic structures of airplanes different concepts were developed in the past. In the focus of this work are profiles made of continuously reinforced extruded aluminum. The production and the used die set of these profiles is presented as well as problems occurring in terms of geometrical inaccuracies of the embedded high strength wires. In addition, this paper attends to the problem of lateral seam weld formation. The interface between the AA-2099 as well as AA-6056 aluminum alloy and the high strength wires Nivaflex and Nanoflex were characterized by metallurgic investigations and push-out tests. As a result it can be stated that a sufficient geometrical accuracy could be achieved and a high interface strength can be accomplished even if a slight gap is still present in the interface layer between matrix and reinforcing element.
\end{abstract}

\section{Introduction}

Demands for reduced costs for aircraft structures, reduced fuel consumption and less emission of green house gases led to the development of a large variety of innovative concepts for lightweight components. One development in the area of metallic structures is the extrusion of continuously reinforced aluminum profiles, usable, for example, as aircraft stringer profiles [1]. The fundamentals of this process have been analyzed and are described by Schomäcker, Schikorra and Weidenmann according to $[2,3,4]$ for the embedding of high strength wires in a base material of AA-6060. It was shown that the reinforcement can significantly increase the strength as well as stiffness, depending on the amount of wires embedded in the profile.

However, the typical aluminum profiles used in aircraft fuselages, for example, in this case stringers in aircrafts are made of high strength alloys of the $2 \mathrm{xxx}$ or $7 \mathrm{xxx}$ series. In this case, a significant increase of profile strength would require an extremely high strength and/or a large volume fraction of the reinforcing elements. Nevertheless even low volume fractions of reinforcement can be useful in fulfilling certain other functions. One example is the use of reinforcing elements as crack stopping elements, which can increase the residual strength of a structure for instance after a previous object damage of the aircraft body. This function is treated within the project "Improvement of material and part properties of aircraft stringers by composite extrusion" of the Collaborative Research Center SFB/TR 10, funded by the German Research Foundation (DFG). The works are carried out at the Institute of Forming Technology and Lightweight Construction (IUL) of the Technical University Dortmund and the Institute of Materials 
Science and Engineering 1 (IWK1) of the University Karlsruhe and are supported with materials, process knowledge, and testing facilities by Alcan, Alcoa, Aleris, Alu Menziken, EADS Innovation Works, Sandvik Materials Technology, and VAC Vacuumschmelze.

When focusing on continuous wire reinforcement, a detailed knowledge about the reinforcement position in the extrusion product is necessary for the application area as well as for the subsequent manufacturing processes like drilling, milling or welding. The position mostly depends on the material flow in the die, however, deflections in the positioning can occur. According to [2], two different kinds of deflections can take place (Fig. 1): The reinforcements are located in the longitudinal weld seam (horizontal deflection), or the reinforcements are placed in the longitudinal weld seam but do not lie on the profile centre line (vertical deflection). The horizontal deflection of the reinforcing element is mostly determined by the supply position and the process parameters, whereas the vertical deflection depends for example on the symmetry of the die and the temperature gradient in the material flow [2].

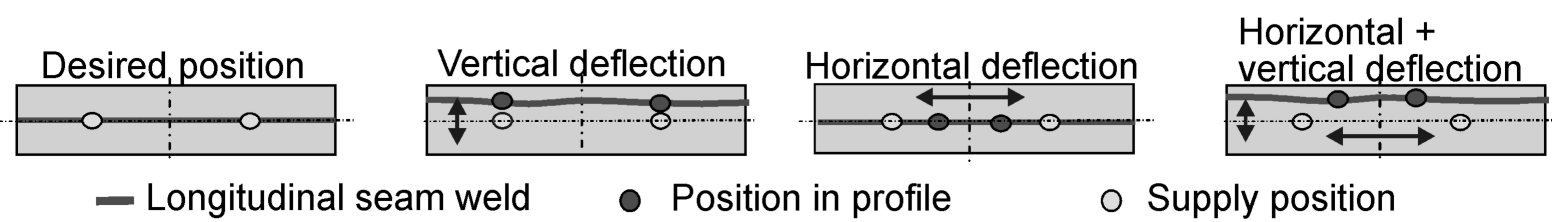

Figure 1: Definition of the horizontal and vertical deflections [2]

\section{Extrusion Setup}

For the extrusion process of aircraft stringer profiles with endless wires made of high strength material a modular tool concept was used. It consists of a sealing plate which divides the base material flow into different feedings, a supply plate with the reinforcing elements being supplied sideways by the use of feeding cartridges, and a die plate which defines the final cross section of the exiting profile (Fig. 2). Initially, before starting the extrusion process, the reinforcement had been supplied manually through feeding holes. At the moment of rejoining the base material strands in the welding chamber, the reinforcing elements are continuously pulled and embedded by the material flow.

Because the maximum press load was limited to $10 \mathrm{MN}$ and the needed extrusion load increases with increasing press ratio the profile geometry has been adapted in the way that two stringer profiles are included in one large profile. Fig. 2 shows the two stringer profiles in the half-finished product. The final shape of the stringer profiles is produced by milling.

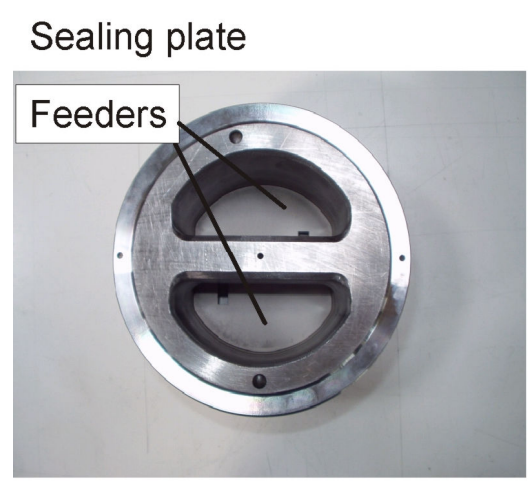

Die plate
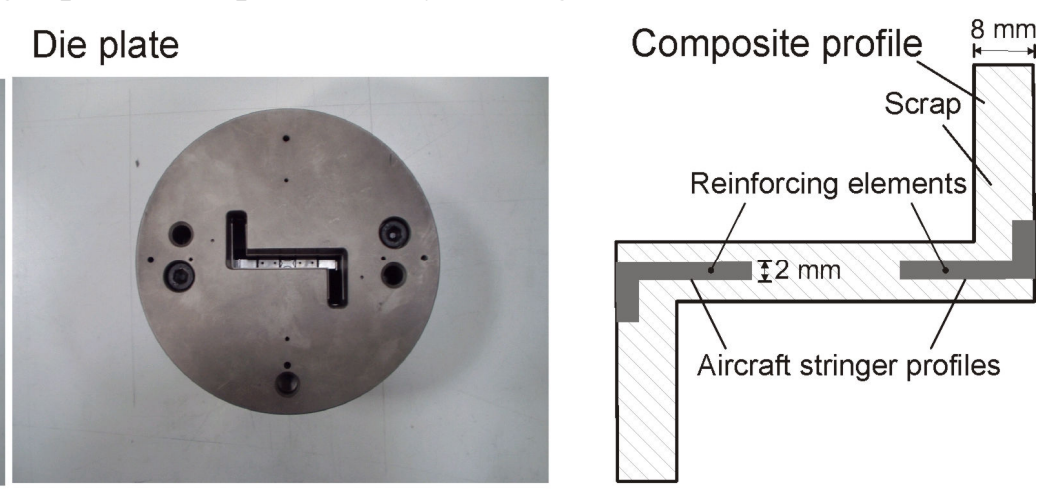

Figure 2: Modular die concept of the tool design and extruded Z-profile cross section

The experiments were carried out using a direct extrusion press, the aircraft aluminum alloys AA-2099 and AA-6056 as base material and the high strength wires Nivaflex and Nanoflex as reinforcement elements. For the extrusion process the AA-2099 billets were preheated to $480^{\circ} \mathrm{C}$ and the billets made of AA- 6056 were preheated to $500^{\circ} \mathrm{C}$. The die was heated to approximately $420^{\circ} \mathrm{C}$ 
and the container to $450^{\circ} \mathrm{C}$. A ram speed of $1 \mathrm{~mm} / \mathrm{s}$ was used. Before extrusion the reinforcement was cleaned manually with acetone.

Former investigations of stringer profile extrusions have shown that the reinforcement has not been fully embedded in the base material, which led to a gap between reinforcement and surrounding base material. To reduce the gap the bearing surfaces were angled $0.5^{\circ}$ normal to the extrusion direction to increase the pressure in the welding chamber, similar to the die modification which is used to improve the welding conditions of the longitudinal seam welds in the industry.

\section{Extrusion Results}

Four billets of AA-6056 and four billets of AA-2099 were extruded to test the homogeneity of the process parameters temperature, punch speed and reinforcement position. In Fig. 3, the die temperature is diagrammed over the extruded profile length for the AA-6056 alloy. The temperature was measured continuously by thermocouples within the die tool package. It can be seen that the temperature increases especially in the first half of every press process and then remains rather stable between $470^{\circ} \mathrm{C}$ and $490^{\circ} \mathrm{C}$. This temperature characteristic is a result of the equilibrium between the billets preheat, heat generated by dissipation when forming the material, and the heat loss at the backup plate. The whole process is not isothermal at all and a change of temperature might lead to a change of the reinforcement element position.

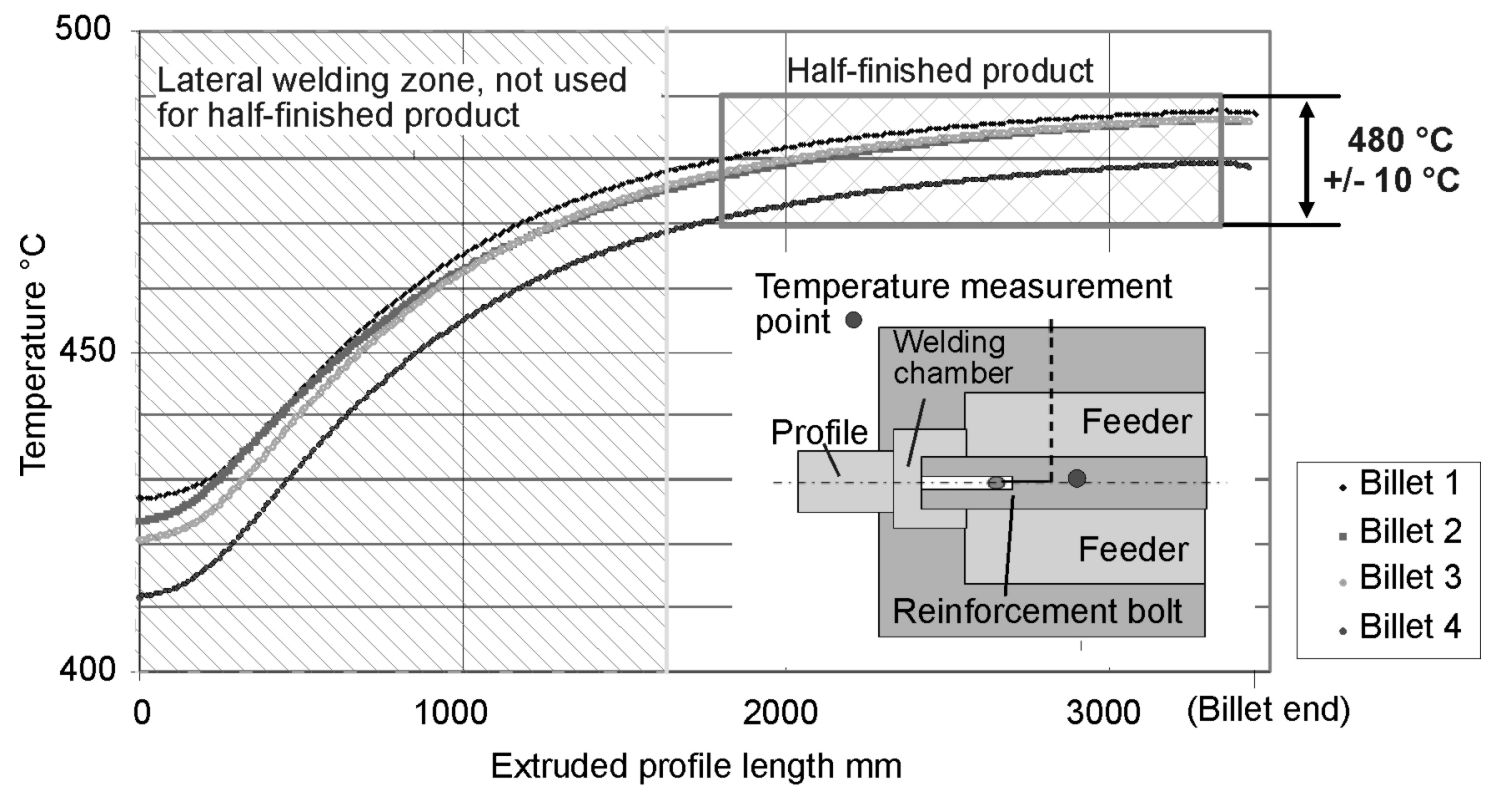

Figure 3: Distribution of the die temperature over the extruded profile length for AA-6056

To analyze the reinforcement position, the profiles were divided into six parts for extracting specimens of a length of approximately $50 \mathrm{~mm}$ (Fig.4). The positioning of the wires in the aluminum base material of the specimens was analyzed with the help of a light optical measurement system.

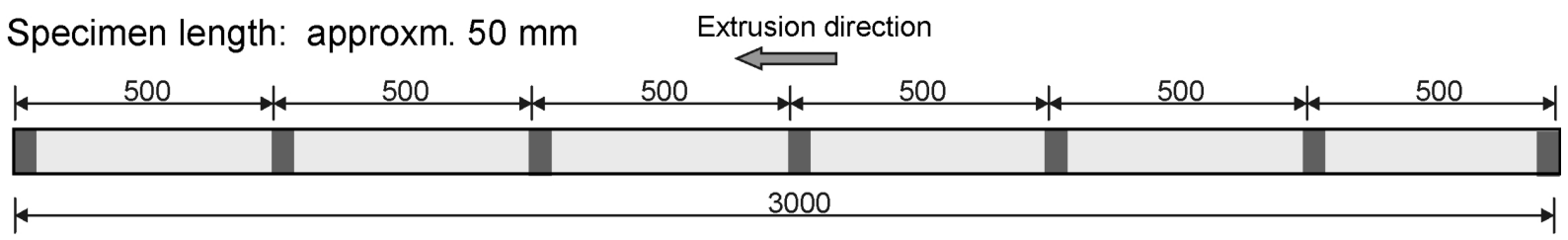

Figure 4: Specimen extraction to analyze the reinforcement position 
In Fig. 5 the mean horizontal deflections are plotted over the profile length for the four billets. The diagram is divided into areas with and without the lateral welding zone. The profile part containing the lateral welding zone is not used for the half-finished product of the aircraft stringer profiles. There is a small mean positive deflection of wire 1 and a small mean negative deflection of wire 2, so that both wires are deflected towards the profile middle. The horizontal positioning error of the wires is not greater than $0.1 \mathrm{~mm}$ and is expected to have no further influence on the testing.
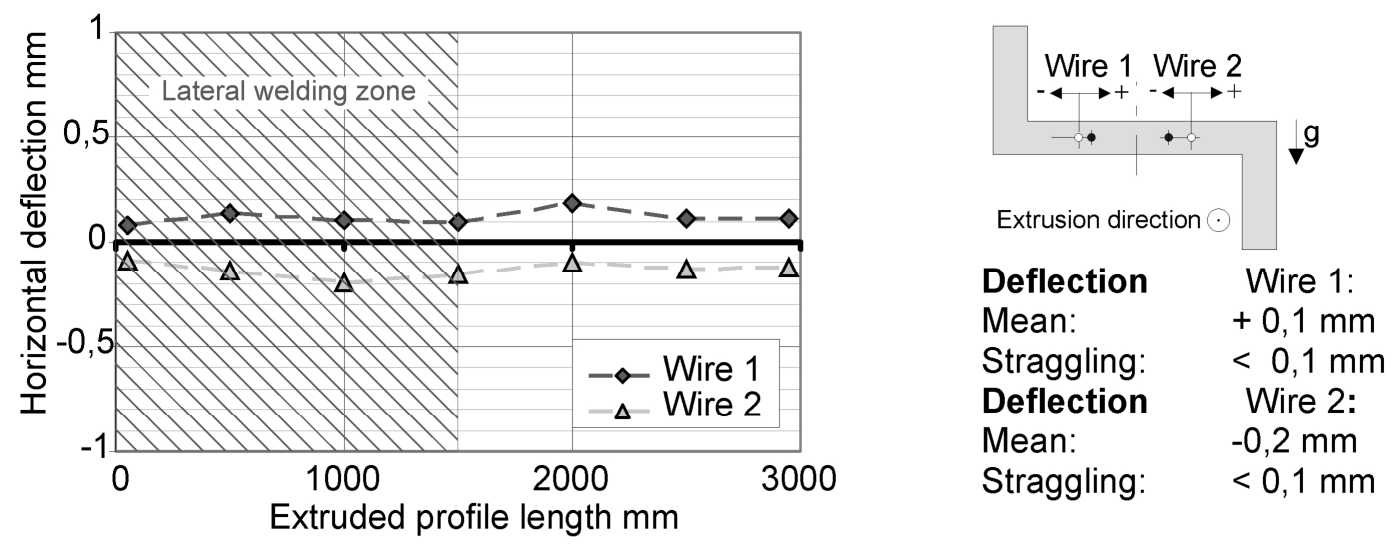

Figure 5: Distribution of the horizontal deflections over the extruded profile length

The vertical deflections of the reinforcement are essential for the further treatment. Large unknown vertical deflections can result in a cutting of the reinforcement elements during the milling process, which is necessary to mill the aircraft stringer profiles from the extruded Z-profile. The vertical deflections are shown in Fig. 6. Again there is a positive deflection of wire 1 and a negative deflection of wire 2 with a variation of less than $0.1 \mathrm{~mm}$. Considering the mean vertical deflections, a high geometrical accuracy can be obtained during the composite extrusion process and the milling of the $2 \mathrm{~mm}$ thick aircraft stringer profiles can be done without the danger of reinforcement cutting.
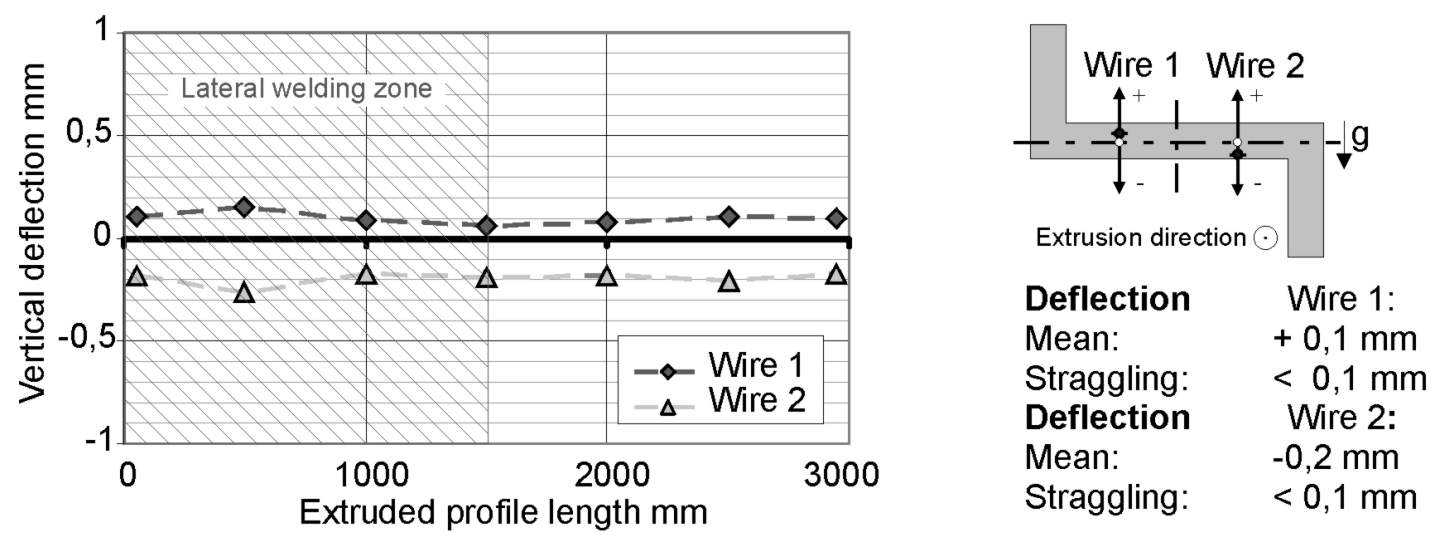

Figure 6: Distribution of the vertical deflections over the extruded profile length

\section{Detection of the Lateral Weld Seam}

Because of the limited maximum press load of the laboratory extrusion press of $10 \mathrm{MN}$ an extrusion of AA-2099 or AA-6056 billets longer than $200 \mathrm{~mm}$ was not possible. Hence it was necessary to stop the extrusion at the end of each billet and to load the next billet for semi-continuous extrusion. Between two billets there is always a billet oxide surface layer leading to a loss of metallic continuity and, consequently, to a lateral weld seam in the extruded profile. To identify the length and characteristic of the lateral weld seam, the faces between two billets were coated with boron nitride before pressing. Since boron nitride is easily detectable after metallographic grinding the 
position of the lateral weld seam could be identified as follows: At the beginning of the lateral weld seam (Fig. 7 a) the new billet material replaces more and more the older one (Fig. $7 \mathrm{~b}+\mathrm{c}$ ) until the older material disappears completely. The replacing starts in the middle of the profile where the speed of the flow of material is highest during the extrusion process.

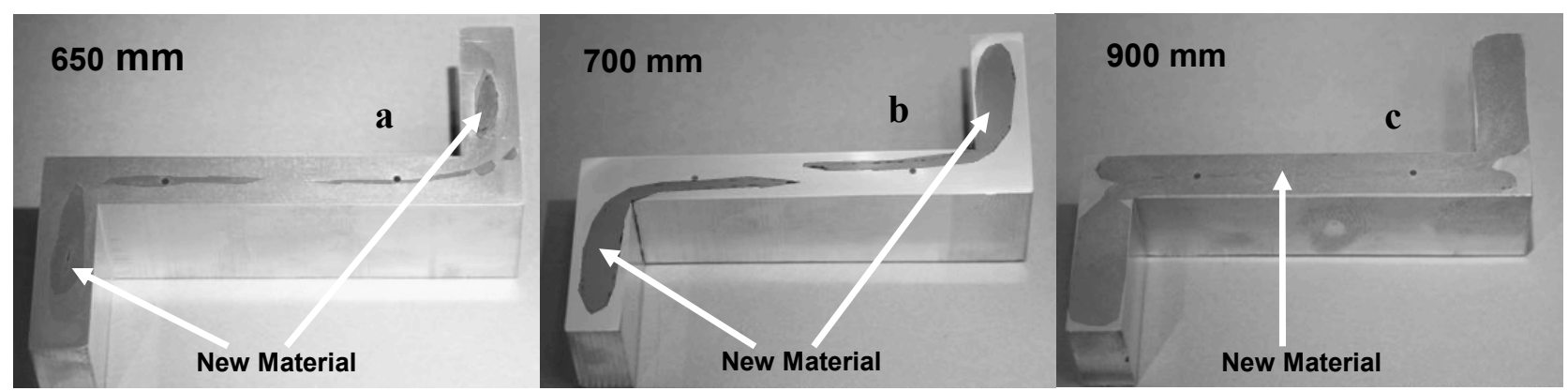

Fig. 7a-c: Distribution of the lateral weld seam at $650 \mathrm{~mm}, 700 \mathrm{~mm}$, and $900 \mathrm{~mm}$ measured from the beginning of the extruded profile

This investigation shows that approximately $1500 \mathrm{~mm}$ of the profile, which is $3100 \mathrm{~mm}$ long, are affected by the lateral weld seam. In order to avoid that a different strength in the lateral weld seam negatively influences the properties of the profiles, this zone has been marked and removed before further investigations were conducted. This left $1600 \mathrm{~mm}$, which did not contain any lateral weld seam and which were then used for the production of the prototype aircraft stringers.

\section{Metallographic Investigations on the Extruded Composite Profile}

To see if the composite is capable of being used as aircraft stringer, it is necessary to analyze quantitatively its interface between reinforcement and base material. In particular, it needs to be tested whether the optimization of the angle of the bearing channels in the die have increased the local pressure and lead to a reduction of the gap between reinforcement and base material that was found in the initial tests. This was realized by metallographic sections. First, a piece of the profile was separated and cold embedded. Afterwards it was ground and polished and finally examined with a light optical microscope.

In certain areas around the wire a slight gap could be still identified between the AA-6056 base material and the Nanoflex wire with a width of approximately $2 \mu \mathrm{m}$ (Fig. 8 a gap "1"). Furthermore, the wire seams locally plastic deformed due to plastic deformation during the embedding process (Fig. 8 a deformation " 2 "). In Fig. 8 b, the AA-2099 is shown with a Nivaflex-wire. Again, a gap is visible at the interface (1) and the wire is also non-circular (2). This indicates that a still higher pressure is needed to close the gaps.
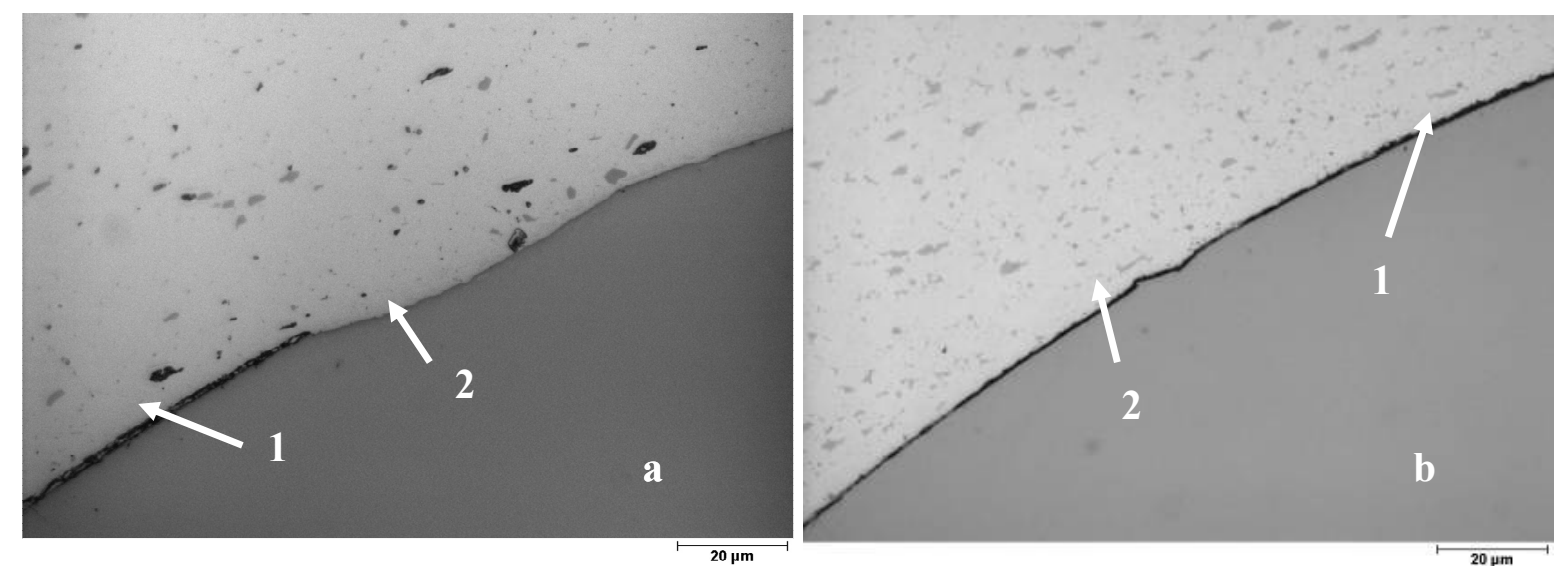

Fig. 8 a: Metallographic section AA-6056 + Nanoflex, 1000x

b: Metallographic section AA-2099 + Nivaflex, 1000x 
After etching the microstructure of AA-6056 showed small grain sizes just around the reinforcing elements and at the border of the profile as well as in the longitudinal seam welds. These areas are those where the highest plastic deformation occurred during the extrusion process.

In addition to this, the microstructure of AA-2099 showed the same formation, but between the regions with fine grains the microstructure partly showed grains larger than in AA-6056.

Compared to the extrusions done before the optimization of the bearing channel angles, the interface quality has improved, but there is still a slight gap left. Future investigations are expected to show whether the gap emerges because of rough separating of the profile and in which way this gap has an influence on the mechanical properties of the profile. In particular, the effect on the debonding shear strength in the interface will be analyzed.

\section{Reinforcement Push-out Tests}

To characterize the mechanical properties of the interface between matrix and reinforcing element, push-out tests [5] were performed. In this test the debonding shear strength is determined by pushing the reinforcing element out of the base material.

The test is carried out on a Zwick Z 2.5 testing machine with a maximum load of $2.5 \mathrm{kN}$. A disc with a thickness of $1 \mathrm{~mm}$, which is cut out of the reinforced profile section, is fixed on the machine and optically adjusted so that the reinforcement is centered. With a micro indenter a force is applied to push the reinforcement out of the base material. The maximum force necessary to reach a debonding of the interface between reinforcement and base material related to the surface of the interface is called the debonding shear strength. The push-out tests were carried out with specimens from a former pressing with AA2099 as matrix material and both wires before the optimization of the die.

The debonding shear strength was in the same range as in former investigations, which were carried out with other alloys and reinforcement materials. While in $[3,6,7]$ values between 61 and $138 \mathrm{MPa}$ depending on the reinforcing element and additional pretreatments of the wire occurred, the interface between base material and Nanoflex wire showed a debonding shear strength of 105 $\mathrm{MPa}$ and between base material and Nivaflex wire $123 \mathrm{MPa}$ without special pretreatments of the wires.

Fig. 9 a shows a scanning electron microscope (SEM) picture of a pushed out Nanoflex-wire from the rear of the push-out specimen. Two conclusions can be drawn from this: First, the base material surrounding the reinforcement element is deformed plastically and, second, there is still base material sticking at the surface of the wires, as can be seen in Fig. 9 b, which shows signs of a dimple fracture. Both observations prove that even with a small gap remaining between wire and base material an excellent base material-wire bonding can be achieved. Future push-out tests on the current profiles are expected to show whether the debonding shear strength increases due to the optimization of the die. 

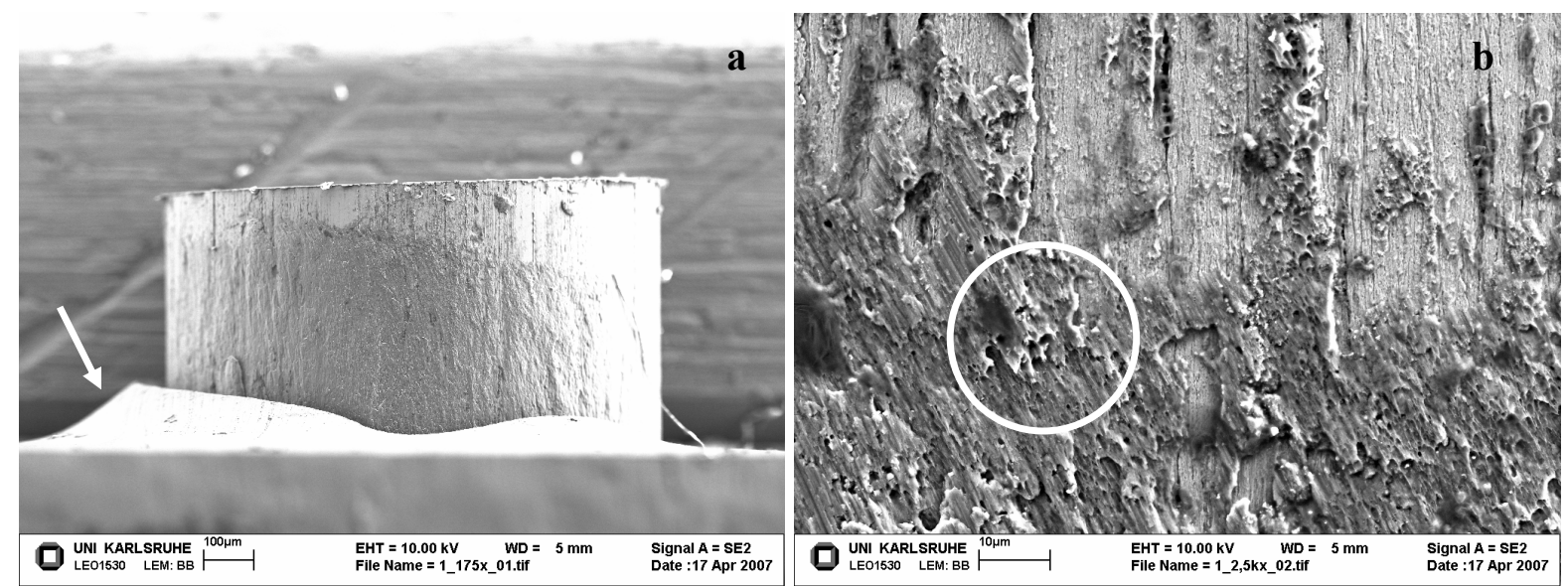

Fig. 9 a: Wire (Nanoflex) pushed out, matrix material is deformed plastically; b: Magnification of the wire surface with aluminum alloy remaining on it

\section{Summary}

This work deals with the extrusion of continuously reinforced profiles for stringer profiles made of high strength AA-2099 and AA-6056 aluminum alloys and high strength wires.

Based on the extruded reinforced profiles the achieved geometrical accuracy of the reinforcement position was analyzed as well as the lateral seam welds. The gap between reinforcement and base material and the resulting debonding shear strength have been discussed. The results can be stated as follows:

1. When embedding the reinforcement, geometrical inaccuracies in horizontal and vertical direction of less than $0.2 \mathrm{~mm}$ occurred in the analyzed profile. This value is in close accordance with former investigations when extruding a relatively weak AA-6060 aluminum alloy. So high process stability can be expected even when changing the alloy.

2. Due to low pressure in the composite development zone a slight gap between reinforcement and base material was found in some areas. An increase in the bearing channel angle reduced this gap, although it was not completely closed.

3. SEM investigations on push-out specimens have shown base material sticking to the pushedout reinforcement. Furthermore, plastic deformations of the base material were visible so that a debonding shear strength is higher than the strength of the base material can be assumed, even if a very small gap between base material and reinforcement remains.

The crack stopping properties of the aircraft stringers will be investigated in future testing.

\section{Acknowledgement}

This paper is based on investigations within the scope of the Transregional Collaborative Research Center/ TR10 and is kindly supported by the German Research Foundation (DFG).

\section{References}

[1] M. Schikorra, M. Schomäcker, T. Kloppenborg, E. Tekkaya, K. Weidenmann, E. Kerscher, D. Löhe: Improved Properties of Aircraft Stringer Profiles by Composite Extrusion, Proceedings of the Applied Production Technology APT'07 conference, Bremen, Germany,285-292, ISBN 978-3-933762-21-4, 2007 
[2] M. Schomäcker: Composite Extrusion of Aluminum Profiles with endless metallic Reinforcements, Dr.-Ing. Dissertation, Institute of Forming Technology and Lightweight Construction, University Dortmund, Shaker publisher, ISBN 978-3-8322-6039-2, 2006

[3] K. A. Weidenmann: Werkstoffsysteme für verbundstranggepresste Aluminiummatrix-verbunde Dr.-Ing. Dissertation, Institute of Material Sciences 1, University Karlsruhe, Shaker publisher, ISBN 978-3832257606, 2006

[4] M. Schikorra: Modeling and Simulation of Composite Extrusion Processes, Dr.-Ing. Dissertation, Institute of Forming Technology and Lightweight Construction, University Dortmund, Shaker publisher, ISBN 978-3832255060, 2006

[5] D. B. Marshall, Journal of the American Ceramics Society, Volume 67, 259-260, 1984

[6] K. A. Weidenmann, E. Kerscher, V. Schulze, D. Löhe: Characterization of the interfacial properties of compound-extruded lightweight profiles using the push-out-technique, Materials Science and Engineering A 424, 205-211, 2006

[7] K. A. Weidenmann, E. Kerscher, V. Schulze, D. Löhe: Grenzflächen in Verbundstrangpressprofilen auf Aluminiumbasis mit verschiedenen Verstärkungselementen, Praktische Metallographie, Volume 37, 131-136, 2005 